\title{
Recent Advances in Electrochemical Glycobiosensing
}

\author{
Germarie Sánchez-Pomales and Rebecca A. Zangmeister \\ Bioprocess Measurements Group, Biochemical Science Division, Material Measurement Laboratory, \\ National Institute of Standards and Technology, 100 Bureau Drive, Gaithersburg, MD 20899, USA \\ Correspondence should be addressed to Rebecca A. Zangmeister, razang@nist.gov
}

Received 16 March 2011; Accepted 8 April 2011

Academic Editor: Bengi Uslu

Copyright ( $) 2011$ G. Sánchez-Pomales and R. A. Zangmeister. This is an open access article distributed under the Creative Commons Attribution License, which permits unrestricted use, distribution, and reproduction in any medium, provided the original work is properly cited.

\begin{abstract}
Biosensors based on electrochemical transduction mechanisms have recently made advances into the field of glycan analysis. These glyco-biosensors offer simple, rapid, sensitive, and economical approaches to the measurement need for rapid glycan analysis for biomarker detection, cancer and disease diagnostics, and bioprocess monitoring of therapeutic glycoproteins. Although the prevalent methods of glycan analysis (high-performance liquid chromatography, mass spectrometry, and nuclear magnetic resonance spectroscopy) provide detailed identification and structural analysis of glycan species, there are significantly few low-cost, rapid glycan assays available for diagnostic and screening applications. Here we review instances in which glycobiosensors have been used for glycan analysis using a variety of electrochemical transduction mechanisms (e.g., amperometric, potentiometric, impedimetric, and voltammetric), selective binding agents (e.g., lectins and antibodies), and redox species (e.g., enzyme substrates, inorganic, and nanomaterial).
\end{abstract}

\section{Introduction}

Glycosylation is the process by which a glycan (i.e., saccharide or carbohydrate) is added to a nonglycan moiety (e.g., protein) and is the most common posttranslational modification of proteins [1]. The glycoforms (i.e., diverse molecular forms of a glycoprotein, resulting from variable glycan structure and/or glycan attachment site occupancy) of a protein profoundly influence structure, function, stability, and serum half-life, which in turn affects many biological processes. Glycosylation plays a role in cell-cell interactions and has been linked to several disease states, including infection, genetic disorders, and cancer [2-4]. In the case of cancer, abnormal protein glycosylation has been linked to early tumor cell growth and proliferation; therefore, glycan-based biomarkers have been sought for early detection [3, 5-9].

Protein glycans are classified as either $\mathrm{N}$-linked or O-linked (Figure 1). N-linked glycans are attached to the peptide at an Asn-X-Ser/Thr sequence site, where $\mathrm{X} \neq$ proline, and share a common branched trimannosyl core. There are three $\mathrm{N}$-glycan subtypes: high-mannose $\mathrm{N}$-glycans which have mannose residues attached to the mannose core, complex $\mathrm{N}$-glycans that do not contain terminal mannose residues but have complex branching, and hybrid N-glycans which contain both mannose residues and complex branching. O-linked glycans tend to be less complex (i.e., linear), they do not share a common single core, and they attach through serine or threonine residues (GalNAc $\alpha 1$ $\mathrm{O}-\mathrm{Ser} / \mathrm{Thr})$. The seven monosaccharides found in human glycoprotein are mannose (Man), glucose (Glc), fucose (Fuc), galactose (Gal), N-acetylgalactosamine (GalNAc), Nacetylglucosamine (GlcNAc), and sialic acid (SA) or neuraminic acid (NeuNAc).

The variation in glycosylation has also been shown to influence the biological activity (efficacy) and immunogenicity (safety) of protein therapeutic drug products, the majority of which are glycosylated [10-12]. Glycoanalysis is required for approval and licensing of protein therapeutic drugs and is used for quality control and process change monitoring [12-14]. With the imminent introduction of biosimilars into the marketplace, glycoanalysis will figure prominently in the determination of "sameness" of generic protein therapeutic drugs. The impact on efficacy and safety of a drug product due to a particular glycan structure 


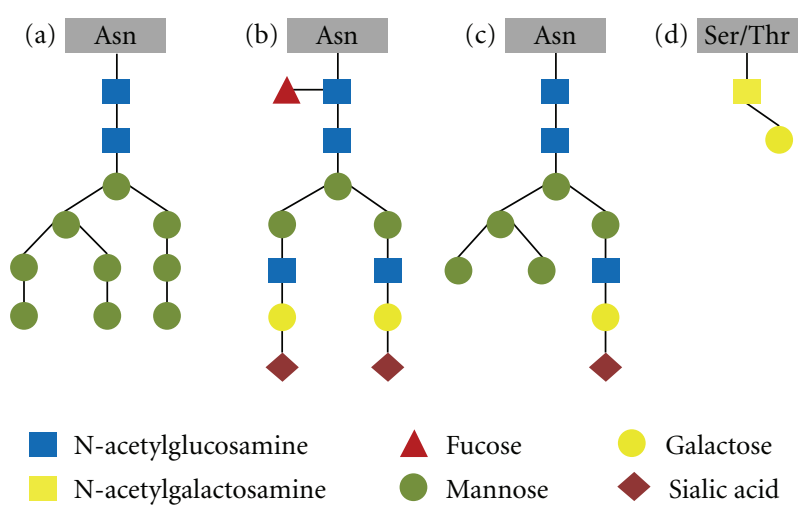

FIGURE 1: Oligosaccharide structure of the most common N-linked (a-c) and O-linked (d) glycans, including (a) high-mannose, (b) complex, and (c) hybrid glycans, and (d) the TF antigen.

or variation in that structure is somewhat unpredictable. Therefore, manufacturers of glycosylated proteins routinely specify and control the observed fractions of glycoforms down to a level dictated by the limit of detection (LOD) and/or limit of quantitation (LOQ) of the glycoanalysis techniques used. One consequence of this is that glycan species representing less than $5 \%$ of the total glycan count may be required to be controlled and specified.

This stringent requirement for characterization of glycan content in biomanufacturing and other areas of research has led to the development of sophisticated glycoanalysis techniques. Glycoanalysis is challenging for several reasons [1]. Unlike other areas of modern biology, such as the ability to predict the peptide sequence of a protein from its RNA and DNA sequences, glycosylation is not template driven and is therefore unpredictable. Glycosylation is inherently heterogeneous with variation found in the identity, relative amounts, and linking of the sugar groups of the oligosaccharide examined $[14,15]$. The chemical structures of sugar subunits can be very similar, with no difference in molecular weight or charge. Even within a population of monoclonal antibodies produced using a cloned cell expression system, and highly monitored growth conditions, a heterogeneous glycan population can exist due to variation in expression levels $[16,17]$. To complicate the analysis further, the glycans can be buried within the protein structure, as is the case for monoclonal antibodies, the largest class of protein therapeutics. Therefore, the glycan is not easily accessible for recognition binding assays and sample preparatory steps must be taken to cleave the glycan off the protein for further chemical and/or structural analysis.

The most common analytical techniques used for complex glycoanalysis include mass spectrometry [19-22], nuclear magnetic resonance spectroscopy [23-26], and separation techniques (e.g., high-performance liquid chromatography and capillary electrophoresis) [27-29]. These methods are well established and are able to provide detailed structural nuclear, making them the most commonly used among nuclear glycoanalysis research centers [30-33]. Although the information gained by these analytical methods is detailed and rigorous, the time and expertise required to carry out these analyses inhibits the application of these methods as diagnostic or screening assays for quality control monitoring of biomanufactured samples, or biomarker screening for disease or infection.

Complete structural detail may not be required for monitoring, screening, or diagnostic applications [34]. Accurate identification and quantitation of the terminal sugar oligo(saccharides) is all that may be required for these types of applications. Although biosensors cannot provide detailed glycosylation information, the level of selectivity and quantitative information they can provide, through the integrated transduction of a biological recognition event to a measureable signal, may be sufficient for high-throughput glycoanalysis measurements by nonspecialist laboratories $[15,34,35]$.

\section{Glycobiosensors}

Glycobiosensors have recently made advances into this area of measurement science. Although sugar analysis by electrochemical methods has a long history (specifically we refer here to the large amount of literature devoted to glucose analysis by the glucose oxidase enzyme electrode [36-39]), the extension to the analysis of the glycan species of glycoconjugates (e.g., glycoproteins and glycopeptides) or cleaved glycan species is rare in comparison. There are several comprehensive reviews on the applications of biosensors for the study of glycans [34, 40] and carbohydrates in general $[41,42]$. These reviews include a range of biosensor designs where the transduction mechanisms include optical (e.g., surface plasmon resonance, SPR), piezoelectric (quartz crystal microbalance, QCM), electrochemical (e.g., electron impedance spectroscopy, EIS or pulsed amperometric detection, PAD), and $\mu$-cantilever deflection. Here we review instances in which glycobiosensors have been used for glycan analysis specifically using a variety of electrochemical transduction mechanisms.

2.1. Electrochemical Glycobiosensors. Electrochemical transduction methods are attractive because they often do not require labeling of the glycan, the physical instrumentation required for electrochemical analysis is often very simple and inexpensive, and the electrode characteristics (e.g., potential window, surface chemistry, and size) can be tailored for specific applications. One of the most widely used applications of electrochemical transduction methods for the analysis of carbohydrates, including cleaved glycans, is the coupling of an efficient separation technique, such as liquid chromatography (LC) or capillary electrophoresis (CE) with PAD. LC-PAD and CE-PAD systems have demonstrated high selectivity for easily oxidized or reduced analytes and limits of detection that rival fluorescence and mass spectrometric techniques [42]. These mature analytical systems have shown significant success over the past few decades. The application of LC, in particular high-performance anion exchange chromatography (HPAEC), and CE with PAD for the determination of oligosaccharide structure and the characterization of potential glycosylation sites has been thoroughly reviewed 
by several groups [42-47]. These reviews discuss the analysis of mixtures of oligosaccharides, glycoproteins, glycopeptides and glycoconjugates by LC-PAD and CE-PAD.

Other electrochemical transduction methods used in glycobiosensor design include differential pulse voltammetry (DPV) [48-54], cyclic voltammetry (CV) [50, 54, 55], electrochemical impedance spectroscopy $[18,53,54,56-64]$, potentiometry $[65,66]$, and square wave voltammetry (SWV) $[67,68]$. This review is focused specifically on biosensor technologies applied to glycoanalysis (i.e., a glycobiosensor) that use electrochemical transduction mechanisms, unless otherwise noted $[69,70]$.

Glycobiosensor designs can be quite complex, due to challenges associated with direct electrochemical analysis of glycans. Although carbohydrates are able to be oxidized using chemical agents, they do not commonly exhibit redox behavior [42]. Similarities in the chemical structure of sugars require the use of a selective binding agent or a separation technique prior to glycoanalysis [42]. The most well-known biosensor design is that of the enzyme electrode applied to the detection of glucose. In this example, the carbohydrate (glucose) is the substrate for the enzyme (glucose oxidase) which is proximal to the electrode surface; the redox active product of the enzymatic reaction is measured at the electrode surface and is proportional to the amount of glucose in solution. This technology was first introduced 50 years ago $[36,38]$, and there are several comprehensive articles that review the history of research in this field [39, 71-75].

The most common types of glycobiosensor design are presented in Figure 2. All of them use selective binding agents; the most common of which are lectins (carbohydratebinding proteins), as will be discussed below, and a redox probe combined with one of the electrochemical transduction techniques listed above, the most common being EIS and DPV. Typically when EIS is used (Figure 2(a)), the electrode (planar or modified with a nanomaterial coating) is modified with a glycan-binding agent (lectin), which imparts selectivity and affinity. Changes in the charge transfer resistance at the electrode in the presence of a redox couple (e.g., $\left.\left[\mathrm{Fe}(\mathrm{CN})_{6}\right]^{3-/ 4-}\right)$ are monitored and interpreted as binding of glycans, glycoconjugates, or cell surface carbohydrates. In the case of a lectin biosensor sandwich assay (Figure 2(b)), a surface-bound lectin selectively attracts a glycan target to the electrode surface, and a second redox active lectin conjugate binds to the captured target. Lastly, in the case of cell surface carbohydrate analysis, the cell is often captured at an electrode surface (planar or modified with a nanomaterial coating), and a lectin-enzyme conjugate in the presence of substrate selectively binds to cell surface carbohydrates and provides the electrochemical signature (Figure 2(c)). As will be seen in specific examples from the literature discussed below, nanomaterials are often incorporated into these biosensor designs either to increase the surface area and subsequently the signal generated at the electrode, or as a redox agent.

Lectins are by far the most commonly used selective binding elements for glycobiosensor measurements. Lectins are naturally occurring carbohydrate-binding proteins that exhibit specificity dependent on the identity of the terminal

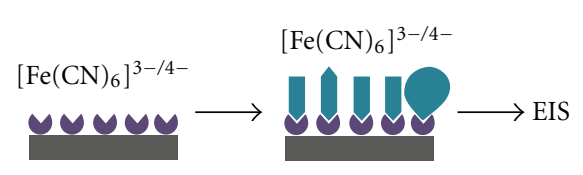

(a)

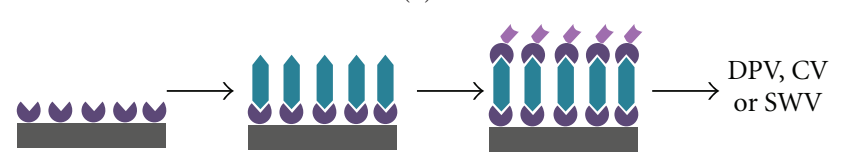

(b)

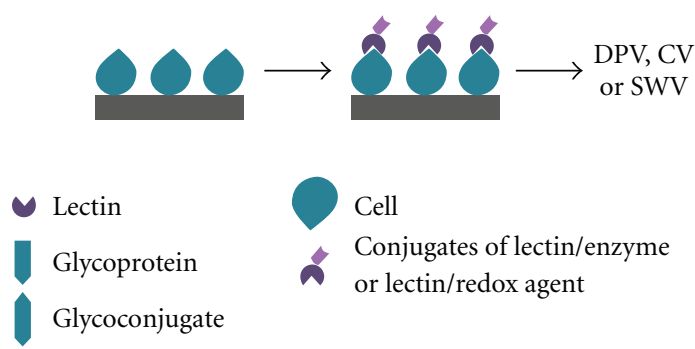

(c)

Figure 2: Schematic showing the most common types of electrochemical biosensors for glycan analysis: (a) electron impedance spectroscopy-(EIS) based assay; (b) a lectin biosensor sandwich assay using differential pulse voltammetry (DPV), cyclic voltammetry $(\mathrm{CV})$, or square wave voltammetry (SWV) detection; (c) surface cell carbohydrate assay using a binding lectin/enzyme conjugate to provide the electrochemical signature detected by DPV, CV, or SWV.

sugar residue of the analyte. Although the specificity of lectins depends primarily on the terminal sugar group, quantitative differences in the affinity of lectins with various carbohydrate sequences, even in the case when the terminal sugar is the same, have been reported [76, 77]. Lectins are used in many areas of glycomic research including biomarker detection, clinical diagnostics, and the understanding of carbohydrate-protein interactions [35, 77-79].

Table 1 lists the lectins used and the sugar-binding specificity [34] for each instance surveyed here. Con A, a mannose/glucose binding lectin, is most often used as a selective pull-down reagent, bringing glycans, glycoconjugates, or cells to planar electrodes $[63,64]$ and to nanomaterial coated electrodes $[18,60,61]$. Covalent bonding of an enzyme (e.g., horseradish peroxidase, HRP) to Con A creates a lectinenzyme conjugate that both binds to the glycan species of interest at the electrode and provides an enzymatically generated redox signal $[48,52]$. Con A has also been used in lectin-glycan-lectin sandwich assays [51].

\subsubsection{Glycobiosensors Based on Electrochemical Impedance Spectroscopy. Electrochemical impedance spectroscopy (EIS) is an efficient, sensitive, rapid, and inexpensive technique suitable for the characterization of transformations on elec- trode surfaces and, therefore, is especially suited for the label- free transduction of biosensing events on electrodes [64]. EIS enables rapid, label-free assays, through the analysis of changes in the properties of the electrode interface associated with analyte binding. In the case of glycan analysis, EIS}


TABLE 1: Lectins used in glycobiosensor applications noted within this manuscript.

\begin{tabular}{lclc}
\hline Lectin & Abbreviation & Major specificity & Reference(s) \\
\hline Concanavalin A & Con A & Man, Glc, GlcNAc & {$[18,48,50-54,56,59-61$,} \\
& & Gal- $\beta(1,3)-$ GalNAc(O-linked & {$[18,48,58,67,83]$} \\
Peanut agglutinin & PNA & GalNAc) & {$[51,57,58][58]$} \\
Sambucus lectin & SNA I & Sialic acid- $\alpha(2,6)$ Gal/GalNAc & {$[18,48,83]$} \\
Horse gram lectin & SNA II & GalNAc & {$[18,48,83]$} \\
Wheat germ agglutinin & DBA & NeuAc/GlcNAc & {$[56]$} \\
Castor bean lectin & WGA & Gal & {$[82]$} \\
Lentil lectin & RCA & Man, Glc, GlcNAc & {$[57]$} \\
Maackia agglutinin & LCA & Sialic acid- $\alpha(2,3)$ & {$[62]$} \\
Cratylia mollis & MAA & Man, Glc & \\
\hline
\end{tabular}

allows for the interrogation of lectin-glycan binding events by monitoring a change in the system impedance, or more specifically, a change in charge transfer resistance $\left(R_{\mathrm{CT}}\right)$ in the presence of a redox couple.

EIS measures the impedance of a system over a range of frequencies through the application of a small-amplitude alternating-current signal. EIS can be used to understand electrochemical reaction rates, and to describe interfaces due to its sensitivity to charge transfer processes that occur at the electrode/electrolyte interface. By fitting EIS data to an equivalent circuit, the value for $R_{\mathrm{CT}}$ (which models charge transfer across the interface) can be obtained. Binding events at the electrode surface would affect $R_{\mathrm{CT}}$, due to the blocking effect that the immobilized molecules have on the charge transfer process; therefore, $R_{\mathrm{CT}}$ (or $\Delta R_{\mathrm{CT}}$ ) can be used as a detection parameter.

Electrochemical impedance spectroscopy, in conjunction with lectins, was used for the first time by La Belle and coworkers for the detection of glycoconjugates on a chipbased biosensor [58]. The plant lectins PNA and SNA (I and II) were covalently attached to a gold electrode previously modified with mercaptohexadecanoic acid, and impedimetric measurements in the presence of the redox couple ferrocyanide/ferricyanide were used to demonstrate binding of artificial and natural glycoconjugates to the lectin-modified gold electrode. An "artificial glycoprotein" construct of gold nanoparticles (AuNP) encapsulated with TF-antigens (Gal $\beta 1-3$ GalNAc), as well as the glycoprotein asialofetuin (ASF), were rapidly detected on PNA-modified electrodes, whereas the glycoprotein fetuin (FET), the sialylated glycoform of ASF, was detected on SNA-modified electrodes with limits of detection as low as $1 \times 10^{-8} \mathrm{~g} / \mathrm{L}$ ( $\left.150 \mathrm{femtomol} / \mathrm{L}\right)$.

Oliveira et al. modified gold electrodes using a sol-gel method with conjugates of lectins and gold nanoparticles and with polyvinyl butyral (PVB) [61]. Using EIS, they studied the interaction between the glycoprotein ovalbumin and the electrodes in the presence of potassium ferrocyanide/ferricyanide in phosphate buffer. The glucose/mannose-specific lectins, Con A, and Cramoll bound ovalbumin, as evidenced by an increase in charge transfer resistance after the addition of the glycoprotein to the electrode. Increases in the concentration of ovalbumin, from $0.025 \mathrm{~g} / \mathrm{L}$ up to $0.2 \mathrm{~g} / \mathrm{L}$, resulted in increases in $R_{\mathrm{CT}}$. These changes were confirmed by cyclic voltammetry.

The AuNP-lectin-PVB electrode prepared by Oliveira and coworkers [61] was also used to create an impedimetric biosensor to detect serum glycoproteins from patients infected by dengue fever (DF) [59]. A large increase in $R_{\mathrm{CT}}$ was obtained when the glycan portion of the glycoproteins present in the sera of patients infected with DF was allowed to interact with Con A in the modified gold electrode. A smaller increase in $R_{\mathrm{CT}}$ was observed when the serum of healthy patients was analyzed, demonstrating that the specific interaction between Con A and glycans can discriminate between sera from healthy and DF patients. A subsequent report by the same group demonstrated that impedimetric measurements with the AuNP-Con A-PVB electrode discriminate between the sera of patients infected by DF and dengue hemorrhagic fever (DHF), due to a higher expression of glycoproteins in the serum of DHF patients, which results in a larger increase in $R_{\mathrm{CT}}$ in comparison to the DF serum [60].

A similar EIS biosensor was fabricated by modifying $\mathrm{Fe}_{3} \mathrm{O}_{4}$ nanoparticles with the lectin Cramoll, mixing them with PVB and depositing them on a gold electrode [62]. The $\mathrm{Fe}_{3} \mathrm{O}_{4}$-Cramoll-PVB electrode was exposed to the glycoprotein fetuin and to sera from patients infected by different dengue serotypes, and increases in impedance were subsequently observed, indicating that the electrode can be used to sense lectin-glycan interactions. This biosensor effectively detected the presence of glycoproteins in just minutes, used small sample volumes, and was able to discriminate between different dengue serotypes.

Label-free impedimetric biosensors (Figure 3) have used the interaction between glycans and lectin-modified electrodes as the recognition principle to analyze the glycan expression on living cells [18]. Furthermore, the specificity of the lectin-glycan interaction enabled the detection, and identification of bacteria [64]. For example, rapid, label-free electrochemical detection, identification, and quantification of different bacteria were achieved by monitoring the impedimetric changes caused by the recognition between 

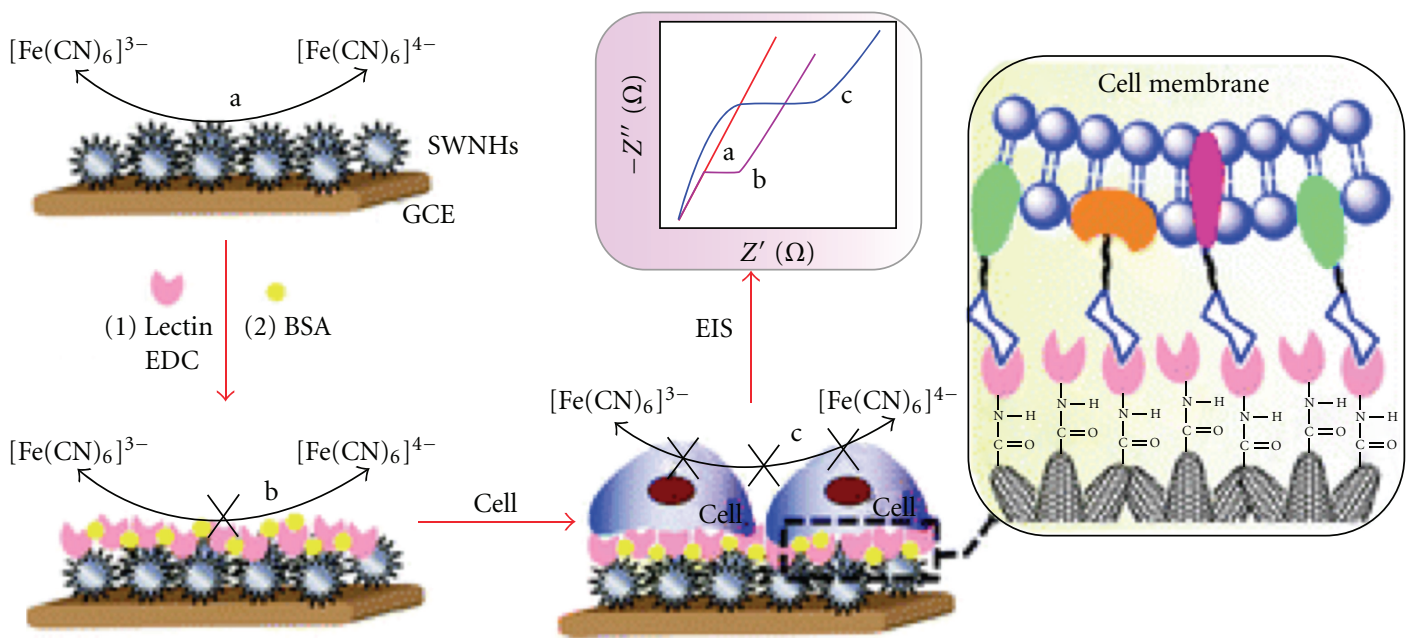

FIGURE 3: Schematic representation of the electrochemical label-free sensor for the analysis of glycan expression on cell surfaces. The sensor was fabricated by modifying a glassy carbon electrode (GCE) with single-walled nanohorns (SWNHs), followed by the covalent attachment of the lectin to the SWNHs, and blocking by bovine serum albumin (BSA). The specific binding between the lectin and the cell membrane carbohydrate was detected by EIS as an increase in charge transfer resistance in the presence of the redox couple $\left[\mathrm{Fe}(\mathrm{CN})_{6}\right]^{3-/ 4-}[18]$. Reproduced with the permission of The Royal Society of Chemistry. http://dx.doi.org/10.1039/B918008G.

lectins and glycan components of bacteria walls. Nine different biotinylated lectins were mixed with the microorganisms, and subsequently deposited on the gold electrode for analysis. The biosensor detected, identified, and quantified three different bacteria with a detection limit and linear range equal to or better than other electrochemical biosensors. Another advantage is that this impedimetric sensor was able to rapidly monitor the change in charge transfer resistance resulting from the interaction between the lectins and the bacteria at gold electrodes without any preconcentration or preenrichment steps. The sensor showed the capability to discriminate between different types of bacteria by using multiplexed analysis with up to nine lectins (Figure 4).

Wan and coworkers fabricated another lectin-based impedimetric biosensor for the rapid and label-free detection of sulfate-reducing bacteria (SRB) at Con A-modified gold electrodes [63]. Con A was covalently attached to a self-assembled monolayer of 11-mercaptoundecanoic acid (MPA) on gold and subsequently allowed to interact with SRB in order to determine and monitor the bacterial growth by impedance measurements in $\left[\mathrm{Fe}(\mathrm{CN})_{6}\right]^{3-/ 4-}$. Several parameters, including solution $\mathrm{pH}$ and incubation time, were optimized, and the concentration of SRB was determined from the charge transfer resistance values obtained by EIS. Additionally, the specificity of the biosensor was investigated by analyzing different types of bacteria, and it was reported that equal concentrations of different species of bacteria (e.g., SBR and Gram-negative bacterium $V$. anguillarum) induced different changes in the $R_{\mathrm{CT}}$ values (Figure 5). The impedimetric biosensor produced SRB growth curves similar to those obtained with the conventional and time-consuming most probable number (MPN) method, thus, demonstrating that EIS has great potential for the rapid, simple and low-cost detection and monitoring of microbial populations. Furthermore, recent work by Xi et al.

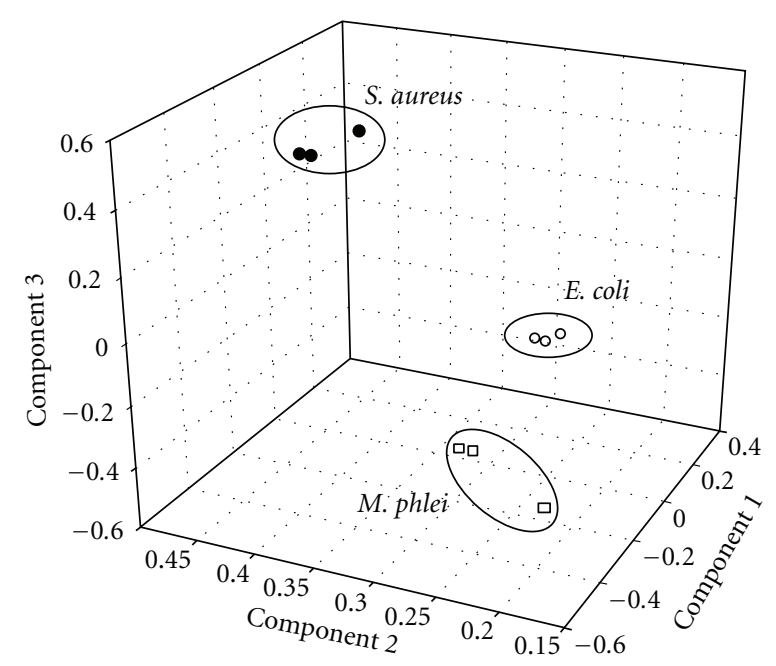

FIGURe 4: Pattern recognition plot obtained from impedimetric measurements using different lectins showing that EIS allows classification and distinction among different types of bacteria. Reprinted from [64], Copyright 2009, with permission from Elsevier.

has shown that a gold electrode modified with lectins by the layer-by-layer self-assembly technique can selectively discriminate Gram-negative bacteria, Gram-positive bacterium, fungus, and mammalian cells by EIS [56].

In related studies, EIS has been used as an effective technique to probe the sugar-binding specificity of lectins using carbohydrate-modified electrodes, composed of boron-doped diamond [80] and gold [81], among others. Furthermore, impedimetric measurements have elucidated the effect of changes in lectin conformation on glucose binding at platinum electrodes [82]. 


\section{Applications: Biomarker and Cell Detection}

Cell surface glycans play significant roles in many key biological processes, including cell differentiation, cell adhesion, cell recognition, and microbial pathogenesis [49]. Aberrant glycosylation patterns of cell surface carbohydrates have been linked to various diseases; thus, it is essential to develop sensitive, reliable, and high-throughput techniques to identify and detect cell surface carbohydrates. Due to their high sensitivity, low cost, simplicity, short assay time and ease of miniaturization, glycobiosensors are a promising alternative for glycan biomarker discovery [57]. In the past few years, glycobiosensors based on electrochemical impedance spectroscopy [57], potentiometry [66], and voltammetry $[48,54,68]$ have been reported for the detection of cell surface glycans and potential biomarkers. Furthermore, insitu imaging of membrane glycan motifs of human gastric carcinoma cells (BGC-823) has been performed by scanning electrochemical microscopy (SECM) [83].

One of the simplest glycobiosensor designs for cell surface glycan monitoring combined the specificity of lectin-glycan binding with the electroactive properties of the ferrocenyl group [50]. Ferrocene monocarboxylic acid $(\mathrm{FcCOOH})$ was covalently conjugated to Con $\mathrm{A}$, and the electroactive species-lectin conjugate was allowed to interact with K562 cells. The cell-Fc-Con A conjugates were unable to diffuse freely to the electrode surface, which, therefore, induced a decrease in differential pulse voltammetry (DPV) peak current, as compared to free Fc-Con A. The magnitude of the decrease in current was proportional to the amount of K562 cells, as well as to the expression extent of mannosepresenting glycans on the cell surface. This simple approach achieved cytosensing and cell surface glycan quantification.

A similar principle (i.e., monitoring a decrease in DPV peak current caused by binding of cells to the electrode) was used for the sensitive detection and quantification of intestinal human colon adenocarcinoma (LS180) cells. This novel glycobiosensor was based on a competition between the specific binding of L-selectin to an aptamer, versus specific binding of L-selectin with glycans on the surface of LS180 cells. Binding of LS180 cells effectively blocked electron transfer between the electroactive species (naphthoquinone) and the electrode, causing a decrease in the DPV peak current.

The principle of double layer capacitive measurements was used by Nagaraj and coworkers to identify glycoform variants of fetuin and differences in glycosylation of protein extracts from a human pancreatic cancer cell line [57]. The sensor, named Nanomonitor, consisted of an array of gold electrodes on a silicon chip that were modified with lectins via biotin/streptavidin linker chemistry. Perturbations of the electrical double-layer occurred when glycans interacted with the lectins, and the perturbations were detected with impedimetric measurements. The sensor distinguished between different synthesized glycoforms of fetuin and differences in glycosylation between protein extracts from human cancerous and normal pancreatic cells. In comparison to lectin-based ELISA assays, the Nanomonitor provided rapid, label-free analysis of glycoproteins with higher

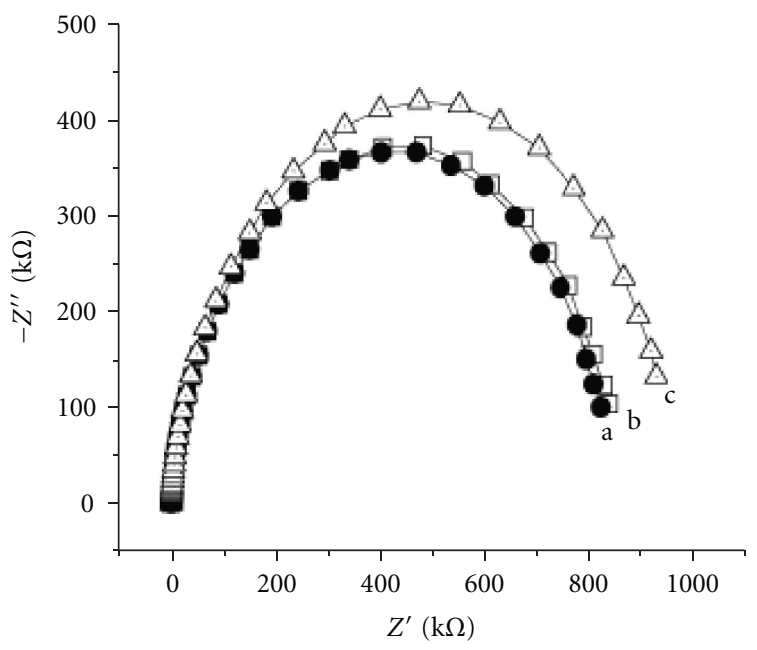

(A)

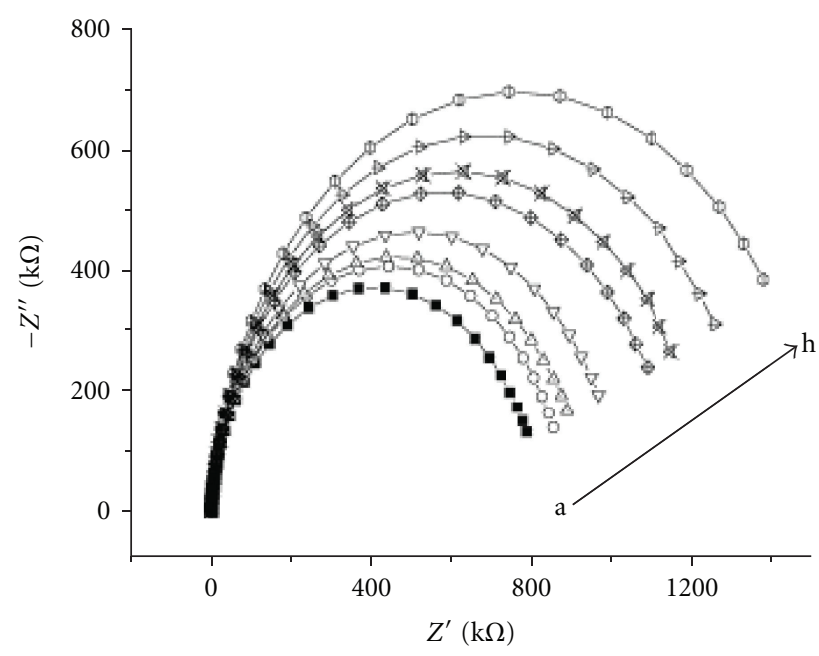

(B)

FIGURE 5: Electrochemical impedance spectra obtained on Con A/MPA/Au electrodes before (a) and after incubation with $V$. anguillarum. (b) and SRB (c) culture samples (A), and at different concentrations of SRB ranging from $1.8 \times 10^{3} \mathrm{cfu}$ (colony forming units)/L to $1.8 \times 10^{10} \mathrm{cfu} / \mathrm{L}$ (B). Reprinted from [63], Copyright 2009, with permission from Elsevier.

sensitivity (five orders of magnitude higher) and a broader dynamic range of glycoprotein concentrations.

Engineered nanomaterials, including nanoparticles [51, 66], nanotubes [48, 52, 54], quantum dots [67, 68, 84], and carbon nanohorns [53], have been used in conjunction with biological binding agents to fabricate glycobiosensors for biomarker detection. For example, single-walled carbon nanotubes functionalized with a short peptide sequence (RGDS, an integrin-binding sequence that inhibits integrin receptor function) were used to capture human leukemic K562 cells on a screen-printed carbon electrode or BGC-823 human gastric carcinoma cells on a glassy carbon electrode 


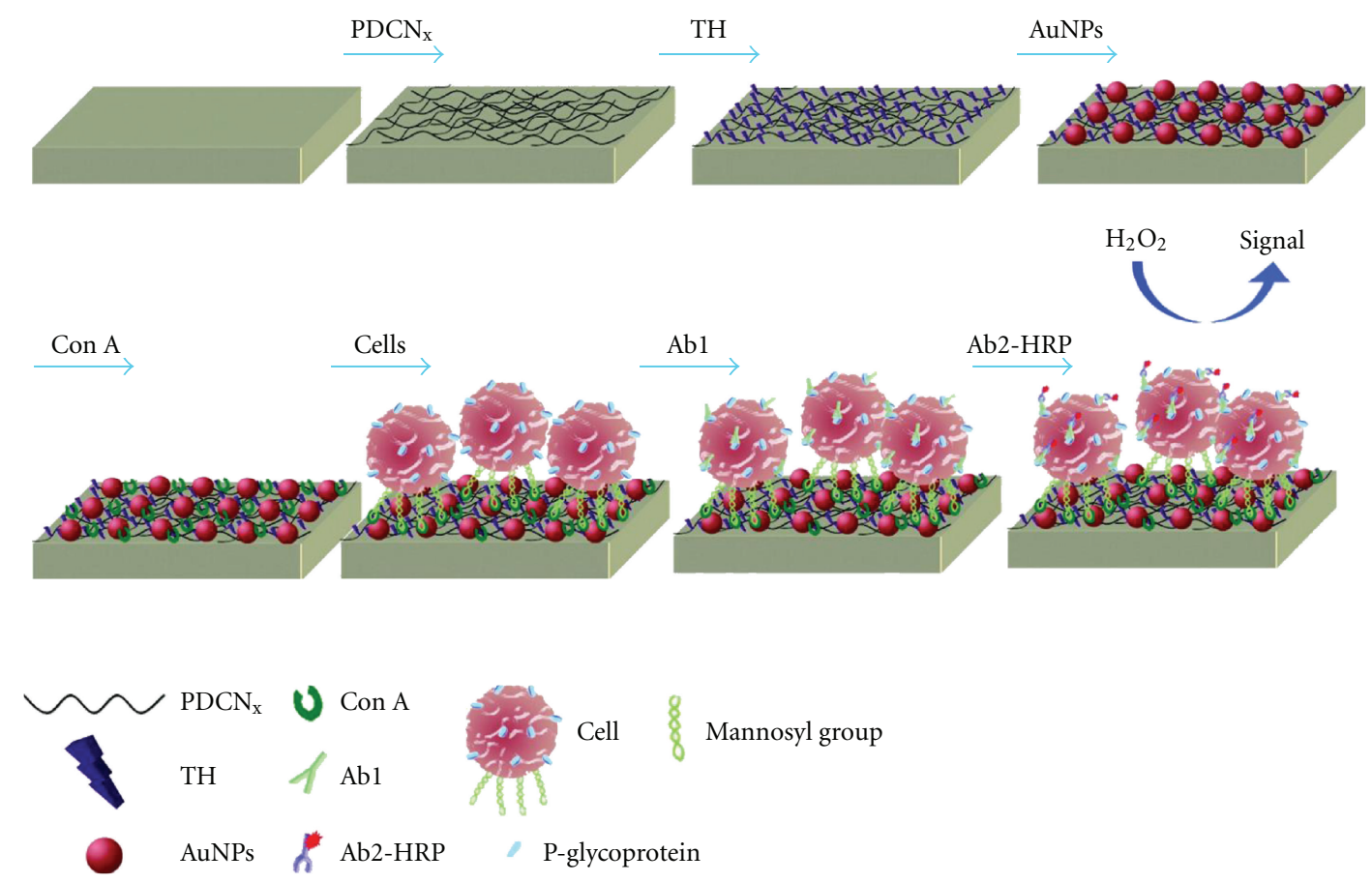

FIGURE 6: Schematic representation of the fabrication of the electrochemical enzyme-linked immunoassay for the detection of cell-surface glycans. Human epithelial carcinoma cells were captured on a glassy carbon electrode modified with nitrogen-doped carbon nanotubes, gold nanoparticles, and Con A. The enzyme HRP was incorporated to the electrode by two-step immunoreactions, and its catalytic reaction towards the oxidation of thionine by $\mathrm{H}_{2} \mathrm{O}_{2}$ was monitored. Reprinted with permission from [54]. Copyright 2010 American Chemical Society.

$[48,52]$. The glycans on the cell wall then captured lectins conjugated to horseradish peroxidase (HRP), and differential pulse voltammetry (DPV) recorded the characteristic electrochemical signal from HRP catalysis in a solution containing $\mathrm{H}_{2} \mathrm{O}_{2}$ and $o$-phenylenediamine. DPV peak currents quantified the amount of lectins captured, which was directly related to the quantity of glycans on the cell surface. The degree of glycan expression on the cancer cell surface and changes in glycan expression after drug treatment were determined with high sensitivity and reproducibility. A variation of this assay showed enhanced sensitivity for the detection of K562 cell wall carbohydrates by combining single-walled carbon nanohorns and gold nanoparticles modified with Con A and HRP [53].

Zhang and coworkers also developed an electrochemical enzyme-linked immunoassay that relied on DPV for the detection of cell surface carbohydrates and an energydependent protein, P-glycoprotein, which can be found on tumor cells [54]. The HRP-catalyzed oxidation of thionine by $\mathrm{H}_{2} \mathrm{O}_{2}$ was monitored by cyclic voltammetry, EIS, and DPV at a glassy carbon electrode modified with nitrogen-doped carbon nanotubes, gold nanoparticles, and Con A (Figure 6). The specific binding between Con A and cell surface mannosyl groups captured human epithelial carcinoma cells. Electrocatalytic peak currents obtained from DPV measurements were correlated to the amount of glycans present on the cell surface. The designed cytosensor, while complex, showed good stability and reproducibility, and a wide linear range and low detection limit for the quantification of Pglycoprotein and cell surface carbohydrates.

Alternatively, the potential shift that occurs when an electrode reacts with an ovarian tumor marker formed the basis for a potentiometric immunoassay for carbohydrate antigen-125 (CA125) [66]. Multifunctional magnetic beads, synthesized using magnetic $\mathrm{Fe}_{3} \mathrm{O}_{4}$ nanoparticles and poly(amidoamine) dendrimer, were used as an affinity support for the immobilization of anti-CA125 and, with the aid of a magnet, were attached on a carbon paste electrode. The potential shift recorded after CA125 was bound to the electrode allowed for the simple, rapid, and sensitive electrochemical detection of the CA125 tumor marker. The detection of the CA125 mucin-like glycoprotein was also achieved by a sandwich-type electrochemical immunoassay using anti-CA125-coated magnetic beads for CA125 capture and immobilization on the electrode, and anti-CA125coated nanosilica particles doped with HRP and thionine for signal enhancement [55].

$\mathrm{Gu}$ et al. developed another sandwich-type immunoassay to detect the carbohydrate antigen 19-9 (CA 19-9), a marker for pancreatic cancer [68]. Conjugates of $\mathrm{ZnO}$ quantum dots and the antibody for CA 19-9 formed a sandwich structure through the immunoreactions with CA 19-9 and a monolayer of CA 19-9 antibody on a silicon wafer. The $\mathrm{ZnO}$ quantum dots linked to the substrate were dissolved in acidic media, and the solution containing $\mathrm{Zn}^{2+}$ was accumulated at the electrode and analyzed by square wave stripping 


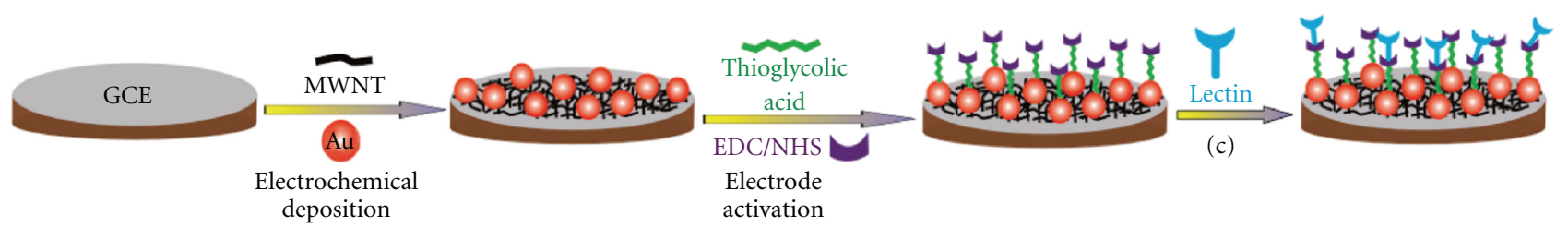

(a)

(b)

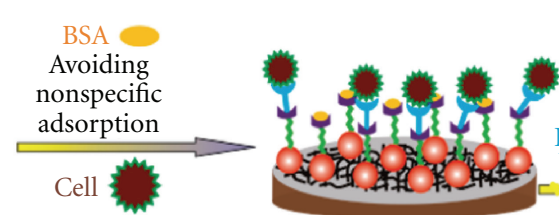

(d)

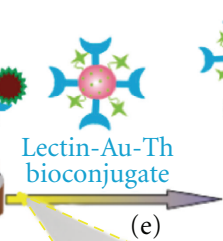

(e)
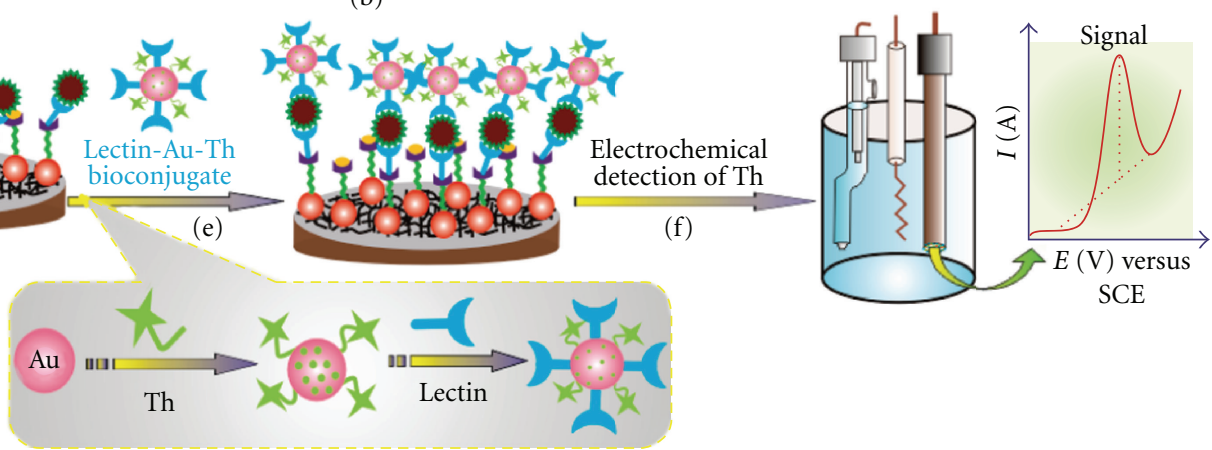

(f)

SCE

FIGURE 7: Schematic of the sandwich-type lectin-based sensor for electrochemical analysis of glycan expression on cells. A glassy carbon electrode was modified with gold nanoparticles, thioglycolic acid and lectins, and nonspecific adsorption to the electrode was blocked by BSA. Cell-surface glycans were bound to the lectin-modified electrode, and gold nanoparticles modified with lectins and thionine were subsequently bound to the cells to create the sandwich. Thionine was detected electrochemically by DPV. Reprinted with permission from [51]. Copyright 2010 American Chemical Society.

voltammetry (SWSV). This reusable immunosensor presented high sensitivity, stability, selectivity, and good reproducibility. Furthermore, SWSV in conjunction with CdS or CdTe quantum dots has also been used to develop competitive assays for the analysis of K562 cell surface carbohydrates [84], and for the detection of the cancer associated T-antigen [67].

The sandwich format was also used to fabricate a lectinbased sensor for the analysis of sialic acid potential biomarkers for human lung, liver, and prostate cancer [51]. A composite film of gold nanoparticles and multiwalled carbon nanotubes immobilized the lectins (Figure 7). Binding of the glycans on the cell wall surface to the lectin-modified electrode, followed by the attachment of gold nanoparticles labeled with lectins and the electroactive species thionine to the immobilized cells, formed the sandwich. The electrochemical signal of thionine was correlated to the carbohydrate expression levels on the cells, and indirectly to the amount of bound cells, therefore allowing cell quantification. A label-free, potentiometric sensor based on the interaction between phenylboronic acid (PBA) and 1,2- or 1,3-diols was applied to the analysis of altered sialic acid expression on erythrocytes as a model for diabetes diagnosis [65]. The previously described glycobiosensors were capable of detecting enhanced expression of sialic acid in cancer cells as compared to normal ones, and differences in sialic acid content in erythrocytes, thus demonstrating that sialic acid could serve as a potential biomarker for different types of cancer, as well as for diabetes mellitus.

\section{Summary}

Glycobiosensors offer simple, rapid, sensitive, and economical approaches to the measurement needs associated with desired rapid glycan analysis for biomarker detection, cancer and disease diagnostics, and bioprocess monitoring of therapeutic glycoproteins. The examples discussed here are generally singular in occurrence, but the successful application of a variety of electrochemical transduction methods, combined with novel redox probes speak to the compatibility of biosensors with glycoanalysis. The high sensitivity and broad dynamic range reported for the Nanomonitor system is one example of how a well-engineered glycobiosensor can offer a rapid and label-free alternative to glycan monitoring by traditional lectin-based ELISA assays. As new information about glycan structure and function is gleaned from glycomics researchers, new glycobiosensors can be developed. In addition to lectin binding agents, the integration of aptamer and antibody binding agents into electrochemical glycobiosensors may improve the specificity of these assays. Further advances in the development of these types of glycobiosensors will help to effectively transfer the knowledge gained from specialist glycoanalysis research facilities into practical low-cost assays for high-throughput analysis that will be accessible for use in clinical and biomanufacturing settings.

\section{Acknowledgment}

Financial support was received by G. S.-Pomales through the National Research Council-Research Associateship Program/NIST postdoctoral fellowship program.

\section{References}

[1] A. Varki et al., Ed., Essentials of Glycobiology, Cold Spring Harbor Press, Cold Spring Harbor, NY, USA, 1999. 
[2] D. H. Dube and C. R. Bertozzi, "Glycans in cancer and inflammation-potential for therapeutics and diagnostics," Nature Reviews Drug Discovery, vol. 4, no. 6, pp. 477-488, 2005.

[3] N. H. Packer, C. W. von der Lieth, K. F. Aoki-Kinoshita et al., "Frontiers in glycomics: bioinformatics and biomarkers in disease: an NIH White Paper prepared from discussions by the focus groups at a workshop on the NIH campus, Bethesda MD (September 11-13, 2006)," Proteomics, vol. 8, no. 1, pp. 8-20, 2008.

[4] H. J. An, S. R. Kronewitter, M. L. A. de Leoz, and C. B. Lebrilla, "Glycomics and disease markers," Current Opinion in Chemical Biology, vol. 13, no. 5-6, pp. 601-607, 2009.

[5] T. Patwa, C. Li, D. M. Simeone et al., "Glycoprotein analysis using protein microarrays and mass spectrometry," Mass Spectrometry Reviews, vol. 29, no. 5, pp. 830-844, 2010.

[6] P. M. Drake, W. Cho, B. Li et al., "Sweetening the pot: adding glycosylation to the biomarker discovery equation," Clinical Chemistry, vol. 56, no. 2, pp. 223-236, 2010.

[7] Y. Qiu, T. H. Patwa, LI. Xu et al., "Plasma glycoprotein profiling for colorectal cancer biomarker identification by lectin glycoarray and lectin blot," Journal of Proteome Research, vol. 7, no. 4, pp. 1693-1703, 2008.

[8] K. Ueda, T. Katagiri, T. Shimada et al., "Comparative profiling of serum glycoproteome by sequential purification of glycoproteins and 2-nitrobenzenesulfenyl (NBS) stable isotope labeling: a new approach for the novel biomarker discovery for cancer," Journal of Proteome Research, vol. 6, no. 9, pp. 34753483, 2007.

[9] H. J. An, S. Miyamoto, K. S. Lancaster et al., "Profiling of glycans in serum for the discovery of potential biomarkers for ovarian cancer," Journal of Proteome Research, vol. 5, no. 7, pp. 1626-1635, 2006.

[10] P. M. Rudd, T. Elliott, P. Cresswell, I. A. Wilson, and R. A. Dwek, "Glycosylation and the immune system," Science, vol. 291, no. 5512, pp. 2370-2376, 2001.

[11] Y. van Kooyk and G. A. Rabinovich, "Protein-glycan interactions in the control of innate and adaptive immune responses," Nature Immunology, vol. 9, no. 6, pp. 593-601, 2008.

[12] G. Walsh and R. Jefferis, "Post-translational modifications in the context of therapeutic proteins," Nature Biotechnology, vol. 24, no. 10, pp. 1241-1252, 2006.

[13] A. J. Chirino and A. Mire-Sluis, "Characteristics biological products and assessing comparability following manufacturing changes," Nature Biotechnology, vol. 22, no. 11, pp. 1383 1391, 2004.

[14] R. Jefferis, "Glycosylation of recombinant antibody therapeutics," Biotechnology Progress, vol. 21, no. 1, pp. 11-16, 2005.

[15] S. A. Brooks, "Strategies for analysis of the glycosylation of proteins: current status and future perspectives," Molecular Biotechnology, vol. 43, no. 1, pp. 76-88, 2009.

[16] M. Butler, "Optimisation of the cellular metabolism of glycosylation for recombinant proteins produced by mammalian cell systems," Cytotechnology, vol. 50, no. 1-3, pp. 57-76, 2006.

[17] N. Jenkins, R. B. Parekh, and D. C. James, "Getting the glycosylation right: implications for the biotechnology industry," Nature Biotechnology, vol. 14, no. 8, pp. 975-981, 1996.

[18] L. Ding, W. Cheng, X. Wang et al., "A label-free strategy for facile electrochemical analysis of dynamic glycan expression on living cells," Chemical Communications, no. 46, pp. 7161$7163,2009$.

[19] A. Dell and H. R. Morris, "Glycoprotein structure determination by mass spectrometry," Science, vol. 291, no. 5512, pp. 2351-2356, 2001.
[20] N. Kawasaki, M. Ohta, S. Hyuga, O. Hashimoto, and T. Hayakawa, "Analysis of carbohydrate heterogeneity in a glycoprotein using liquid chromatography/mass spectrometry and liquid chromatography with tandem mass spectrometry," Analytical Biochemistry, vol. 269, no. 2, pp. 297-303, 1999.

[21] A. Lim, A. Reed-Bogan, and B. J. Harmon, "Glycosylation profiling of a therapeutic recombinant monoclonal antibody with two N-linked glycosylation sites using liquid chromatography coupled to a hybrid quadrupole time-of-flight mass spectrometer," Analytical Biochemistry, vol. 375, no. 2, pp. 163-172, 2008.

[22] A. Zamfir and J. Peter-Katalinić, "Capillary electrophoresismass spectrometry for glycoscreening in biomedical research," Electrophoresis, vol. 25, no. 13, pp. 1949-1963, 2004.

[23] B. Meyer and T. Peters, "NMR spectroscopy techniques for screening and identifying ligand binding to protein receptors," Angewandte Chemie International Edition, vol. 42, no. 8, pp. 864-890, 2003.

[24] H. J. Gabius, H. C. Siebert, S. André, J. Jiménez-Barbero, and H. Rüdiger, "Chemical biology of the sugar code," ChemBioChem, vol. 5, no. 6, pp. 740-764, 2004.

[25] M. R. Wormald, A. J. Petrescu, Y. L. Pao, A. Glithero, T. Elliott, and R. A. Dwek, "Conformational studies of oligosaccharides and glycopeptides: complementarity of NMR, X-ray crystallography, and molecular modelling," Chemical Reviews, vol. 102, no. 2, pp. 371-386, 2002.

[26] J. Ø. Duus, C. H. Gotfredsen, and K. Bock, "Carbohydrate structural determination by NMR spectroscopy: modern methods and limitations," Chemical Reviews, vol. 100, no. 12, pp. 4589-4614, 2000.

[27] N. Blow, "Glycobiology: a spoonful of sugar," Nature, vol. 457, no. 7229, pp. 617-620, 2009.

[28] S. Kamoda and K. Kakehi, "Capillary electrophoresis for the analysis of glycoprotein pharmaceuticals," Electrophoresis, vol. 27, no. 12, pp. 2495-2504, 2006.

[29] P. M. Rudd, H. C. Joao, E. Coghill et al., "Glycoforms modify the dynamic stability and functional activity of an enzyme," Biochemistry, vol. 33, no. 1, pp. 17-22, 1994.

[30] Y. Wada, A. Dell, S. M. Haslam et al., "Comparison of methods for profiling $\mathrm{O}$-glycosylation: human proteome organisation human disease glycomics/proteome initiative multiinstitutional study of IgA1," Molecular \& Cellular Proteomics, vol. 9, no. 4, pp. 719-727, 2010.

[31] Y. Wada, P. Azadi, C. E. Costello et al., "Comparison of the methods for profiling glycoprotein glycans-HUPO human disease glycomics/proteome initiative multiinstitutional study," Glycobiology, vol. 17, no. 4, pp. 411-422, 2007.

[32] S. Thobhani, C. T. Yuen, M. J. A. Bailey, and C. Jones, "Identification and quantification of $\mathrm{N}$-linked oligosaccharides released from glycoproteins: an inter-laboratory study," Glycobiology, vol. 19, no. 3, pp. 201-211, 2009.

[33] A. Beck, E. Wagner-Rousset, M. C. Bussat et al., "Trends in glycosylation, glycoanalysis and glycoengineering of therapeutic antibodies and Fc-fusion proteins," Current Pharmaceutical Biotechnology, vol. 9, no. 6, pp. 482-501, 2008.

[34] S. Cunningham, J. Q. Gerlach, M. Kane, and L. Joshi, "Glycobiosensors: recent advances and applications for the detection of free and bound carbohydrates," Analyst, vol. 135, no. 10, pp. 2471-2480, 2010.

[35] J. Hirabayashi, "Lectin-based structural glycomics: glycoproteomics and glycan profiling," Glycoconjugate Journal, vol. 21, no. 1-2, pp. 35-40, 2004. 
[36] L. C. Clark and C. Lyons, "Electrode systems for continuous monitoring in cardiovascular surgery," Annals of the New York Academy of Sciences, vol. 102, pp. 29-45, 1962.

[37] J. Wang, "Electrochemical glucose biosensors," Chemical Reviews, vol. 108, no. 2, pp. 814-825, 2008.

[38] S. J. Updike and G. P. Hicks, "The enzyme electrode," Nature, vol. 214, no. 5092, pp. 986-988, 1967.

[39] J. Wang, "Glucose biosensors: 40 years of advances and challenges," Electroanalysis, vol. 13, no. 12, pp. 983-988, 2001.

[40] J. Q. Gerlach, S. Cunningham, M. Kane, and L. Joshi, "Glycobiomimics and glycobiosensors," Biochemical Society Transactions, vol. 38, no. 5, pp. 1333-1336, 2010.

[41] R. Jelinek and S. Kolusheva, "Carbohydrate biosensors," Chemical Reviews, vol. 104, no. 12, pp. 5987-6015, 2004.

[42] R. P. Baldwin, "Electrochemical determination of carbohydrates: enzyme electrodes and amperometric detection in liquid chromatography and capillary electrophoresis," Journal of Pharmaceutical and Biomedical Analysis, vol. 19, no. 1-2, pp. 69-81, 1999.

[43] T. R. I. Cataldi, C. Campa, and G. E. De Benedetto, "Carbohydrate analysis by high-performance anion-exchange chromatography with pulsed amperometric detection: the potential is still growing," Fresenius' Journal of Analytical Chemistry, vol. 368, no. 8, pp. 739-758, 2000.

[44] P. L. Weber and S. M. Lunte, "Capillary electrophoresis with pulsed amperometric detection of carbohydrates and glycopeptides," Electrophoresis, vol. 17, no. 2, pp. 302-309, 1996.

[45] M. R. Hardy and R. R. Townsend, "Separation of positional isomers of oligosaccharides and glycopeptides by highperformance anion-exchange chromatography with pulsed amperometric detection," Proceedings of the National Academy of Sciences of the United States of America, vol. 85, no. 10, pp. 3289-3293, 1988.

[46] M. W. Spellman, "Carbohydrate characterization of recombinant glycoproteins of pharmaceutical interest," Analytical Chemistry, vol. 62, no. 17, pp. 1714-1722, 1990.

[47] R. R. Townsend, "Analysis of glycoconjugates using high-pH anion-exchange chromatography," in Carbohydrate Analysis, Z. El Rassi, Ed., pp. 181-209, Elsevier, Amsterdam, The Netherlands, 1995.

[48] W. Cheng, L. Ding, S. Ding, Y. Yin, and H. Ju, "A simple electrochemical cytosensor array for dynamic analysis of carcinoma cell surface glycans," Angewandte Chemie International Edition, vol. 48, no. 35, pp. 6465-6468, 2009.

[49] Z. Shao, Y. Li, Q. Yang, J. Wang, and G. Li, "A novel electrochemical method to detect cell surface carbohydrates and target cells," Analytical and Bioanalytical Chemistry, vol. 398, no. 7-8, pp. 2963-2967, 2010.

[50] Y. Xue, L. Ding, J. Lei, and H. Ju, "A simple electrochemical lectin-probe for in situ homogeneous cytosensing and facile evaluation of cell surface glycan," Biosensors \& Bioelectronics, vol. 26, no. 1, pp. 169-174, 2010.

[51] X. Zhang, Y. Teng, Y. Fu et al., "Lectin-based biosensor strategy for electrochemical assay of glycan expression on living cancer cells," Analytical Chemistry, vol. 82, no. 22, pp. 9455-9460, 2010.

[52] W. Cheng, L. Ding, J. Lei, S. Ding, and H. Ju, "Effective cell capture with tetrapeptide-functionalized carbon nanotubes and dual signal amplification for cytosensing and evaluation of cell surface carbohydrate," Analytical Chemistry, vol. 80, no. 10 , pp. 3867-3872, 2008.
[53] L. Ding, Q. Ji, R. Qian, W. Cheng, and J. Huangxian, "Lectinbased nanoprobes functionalized with enzyme for highly sensitive electrochemical monitoring of dynamic carbohydrate expression on living cells," Analytical Chemistry, vol. 82, no. 4, pp. 1292-1298, 2010.

[54] J. J. Zhang, F. F. Cheng, T. T. Zheng, and J. J. Zhu, "Design and implementation of electrochemical cytosensor for evaluation of cell surface carbohydrate and glycoprotein," Analytical Chemistry, vol. 82, no. 9, pp. 3547-3555, 2010.

[55] D. Tang, B. Su, J. Tang, J. Ren, and G. Chen, "Nanoparticlebased sandwich electrochemical immunoassay for carbohydrate antigen 125 with signal enhancement using enzymecoated nanometer-sized enzyme-doped silica beads," Analytical Chemistry, vol. 82, no. 4, pp. 1527-1534, 2010.

[56] F. Xi, J. Gao, J. Wang, and Z. Wang, "Discrimination and detection of bacteria with a label-free impedimetric biosensor based on self-assembled lectin monolayer," Journal of Electroanalytical Chemistry, vol. 656, no. 1-2, pp. 252-257, 2011.

[57] V. J. Nagaraj, S. Aithal, S. Eaton, M. Bothara, P. Wiktor, and S. Prasad, "NanoMonitor: a miniature electronic biosensor for glycan biomarker detection," Nanomedicine, vol. 5, no. 3, pp. 369-378, 2010.

[58] J. T. La Belle, J. Q. Gerlach, S. Svarovsky, and L. Joshi, "Labelfree impedimetric detection of glycan-lectin interactions," Analytical Chemistry, vol. 79, no. 18, pp. 6959-6964, 2007.

[59] M. D. L. Oliveira, M. T. S. Correia, and F. B. Diniz, "A novel approach to classify serum glycoproteins from patients infected by dengue using electrochemical impedance spectroscopy analysis," Synthetic Metals, vol. 159, no. 21-22, pp. 2162-2164, 2009.

[60] M. D. L. Oliveira, M. T. S. Correia, and F. B. Diniz, "Concanavalin A and polyvinyl butyral use as a potential dengue electrochemical biosensor," Biosensors \& Bioelectronics, vol. 25, no. 4, pp. 728-732, 2009.

[61] M. D. L. Oliveira, M. T. S. Correia, L. C. B. B. Coelho, and F. B. Diniz, "Electrochemical evaluation of lectin-sugar interaction on gold electrode modified with colloidal gold and polyvinyl butyral," Colloids and Surfaces B, vol. 66, no. 1, pp. 13-19, 2008.

[62] M. D. L. Oliveira, M. L. Nogueira, M. T. S. Correia, L. C. B. B. Coelho, and C. A. S. Andrade, "Detection of dengue virus serotypes on the surface of gold electrode based on Cratylia mollis lectin affinity," Sensors and Actuators B, vol. 155, no. 2, pp. 789-795, 2011.

[63] Y. Wan, D. Zhang, and B. Hou, "Monitoring microbial populations of sulfate-reducing bacteria using an impedimetric immunosensor based on agglutination assay," Talanta, vol. 80, no. 1, pp. 218-223, 2009.

[64] M. Gamella, S. Campuzano, C. Parrado, A. J. Reviejo, and J. M. Pingarrón, "Microorganisms recognition and quantification by lectin adsorptive affinity impedance," Talanta, vol. 78, no. 4-5, pp. 1303-1309, 2009.

[65] A. Matumoto, N. Sato, H. Cabral, K. Kataoka, and Y. Miyahara, "Label free potentiometric sialic acid detection applicable to living cell diagnosis," in IEEE Sensors Conference (SENSORS '09), pp. 1885-1888, October 2009.

[66] X. H. Fu, "Poly(amidoamine) dendrimer-functionalized magnetic beads as an immunosensing probe for electrochemical immunoassay for carbohydrate antigen-125 in human serum," Analytical Letters, vol. 43, no. 3, pp. 455-465, 2010.

[67] Z. Dai, A. N. Kawde, Y. Xiang et al., "Nanoparticle-based sensing of glycan-lectin interactions," Journal of the American Chemical Society, vol. 128, no. 31, pp. 10018-10019, 2006. 
[68] B. Gu, C. Xu, C. Yang, S. Liu, and M. Wang, "ZnO quantum dot labeled immunosensor for carbohydrate antigen 19-9," Biosensors \& Bioelectronics, vol. 26, no. 5, pp. 2720-2723, 2011.

[69] D. R. Thevenot, K. Toth, R. A. Durst et al., "Electrochemical biosensors: recommended definitions and classification(technical report)," Pure and Applied Chemistry, vol. 71, no. 12, pp. 2333-2348, 1999.

[70] D. R. Thévenot, K. Toth, R. A. Durst, and G. S. Wilson, "Electrochemical biosensors: recommended definitions and classification," Biosensors \& Bioelectronics, vol. 16, no. 1-2, pp. 121-131, 2001.

[71] E. H. Yoo and S. Y. Lee, "Glucose biosensors: an overview of use in clinical practice," Sensors, vol. 10, no. 5, pp. 4558-4576, 2010.

[72] A. Heller and B. Feldman, "Electrochemical glucose sensors and their applications in diabetes management," Chemical Reviews, vol. 108, no. 7, pp. 2482-2505, 2008.

[73] G. S. Wilson and Y. Hu, "Enzyme-based biosensors for in vivo measurements," Chemical Reviews, vol. 100, no. 7, pp. 26932704, 2000.

[74] N. S. Oliver, C. Toumazou, A. E. G. Cass, and D. G. Johnston, "Glucose sensors: a review of current and emerging technology," Diabetic Medicine, vol. 26, no. 3, pp. 197-210, 2009.

[75] J. D. Newman and A. P. F. Turner, "Home blood glucose biosensors: a commercial perspective," Biosensors \& Bioelectronics, vol. 20, no. 12, pp. 2435-2453, 2005.

[76] A. M. Wu, "Carbohydrate structural units in glycoproteins and polysaccharides as important ligands for Gal and GalNAc reactive lectins," Journal of Biomedical Science, vol. 10, no. 6, pp. 676-688, 2003.

[77] A. M. Wu, E. Lisowska, M. Duk, and Z. Yang, "Lectins as tools in glycoconjugate research," Glycoconjugate Journal, vol. 26, no. 8, pp. 899-913, 2009.

[78] D. Mislovičová, P. Gemeiner, A. Kozarova, and T. Kožár, "Lectinomics I. Relevance of exogenous plant lectins in biomedical diagnostics," Biologia, vol. 64, no. 1, pp. 1-19, 2009.

[79] P. Gemeiner, D. Mislovičová, J. Tkáč et al., "Lectinomics. II. A highway to biomedical/clinical diagnostics," Biotechnology Advances, vol. 27, no. 1, pp. 1-15, 2009.

[80] S. Szunerits, J. Niedziolka-Jonsson, R. Boukherroub, P. Woisel, J.-S. Baumann, and A. Siriwardena, "Label-free detection of lectins on carbohydrate-modified boron-doped diamond surfaces," Analytical Chemistry, vol. 82, no. 19, pp. 8203-8210, 2010.

[81] L. Tan, Q. Xie, and S. Yao, "Electrochemical piezoelectric quartz crystal impedance study on the interaction between concanavalin A and glycogen at Au electrodes," Bioelectrochemistry, vol. 70, no. 2, pp. 348-355, 2007.

[82] R. R. Ueta and F. B. Diniz, "Adsorption of concanavalin $A$ and lentil lectin on platinum electrodes followed by electrochemical impedance spectroscopy: effect of protein state," Colloids and Surfaces B, vol. 61, no. 2, pp. 244-249, 2008.

[83] Y. Xue, L. Ding, J. Lei, F. Yan, and H. Ju, "In situ electrochemical imaging of membrane glycan expression on micropatterned adherent single cells," Analytical Chemistry, vol. 82, no. 17, pp. 7112-7118, 2010.

[84] L. Ding, W. Cheng, X. Wang, S. Ding, and H. Ju, "Carbohydrate monolayer strategy for electrochemical assay of cell surface carbohydrate," Journal of the American Chemical Society, vol. 130, no. 23, pp. 7224-7225, 2008. 


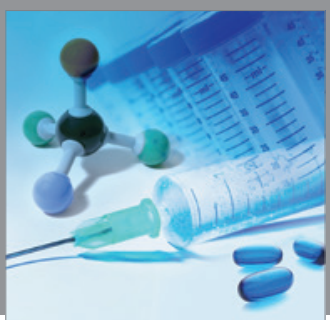

International Journal of

Medicinal Chemistry

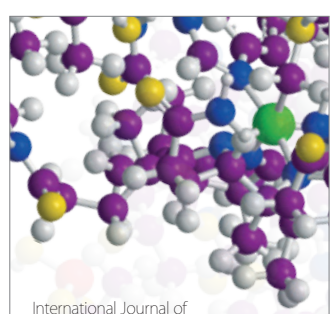

Carbohydrate Chemistry

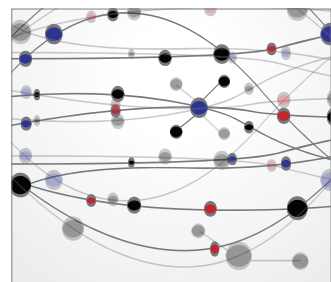

The Scientific World Journal
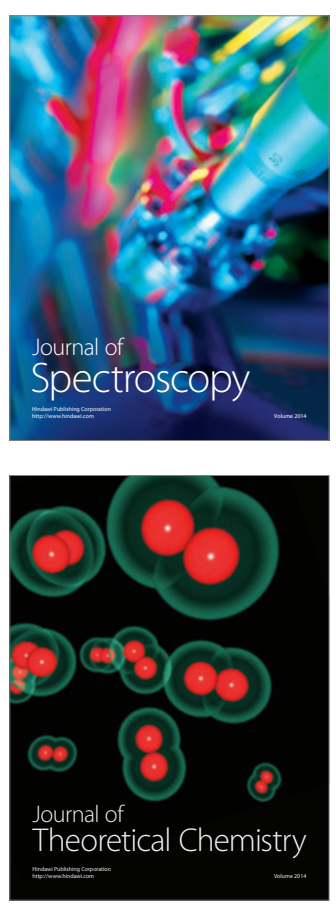
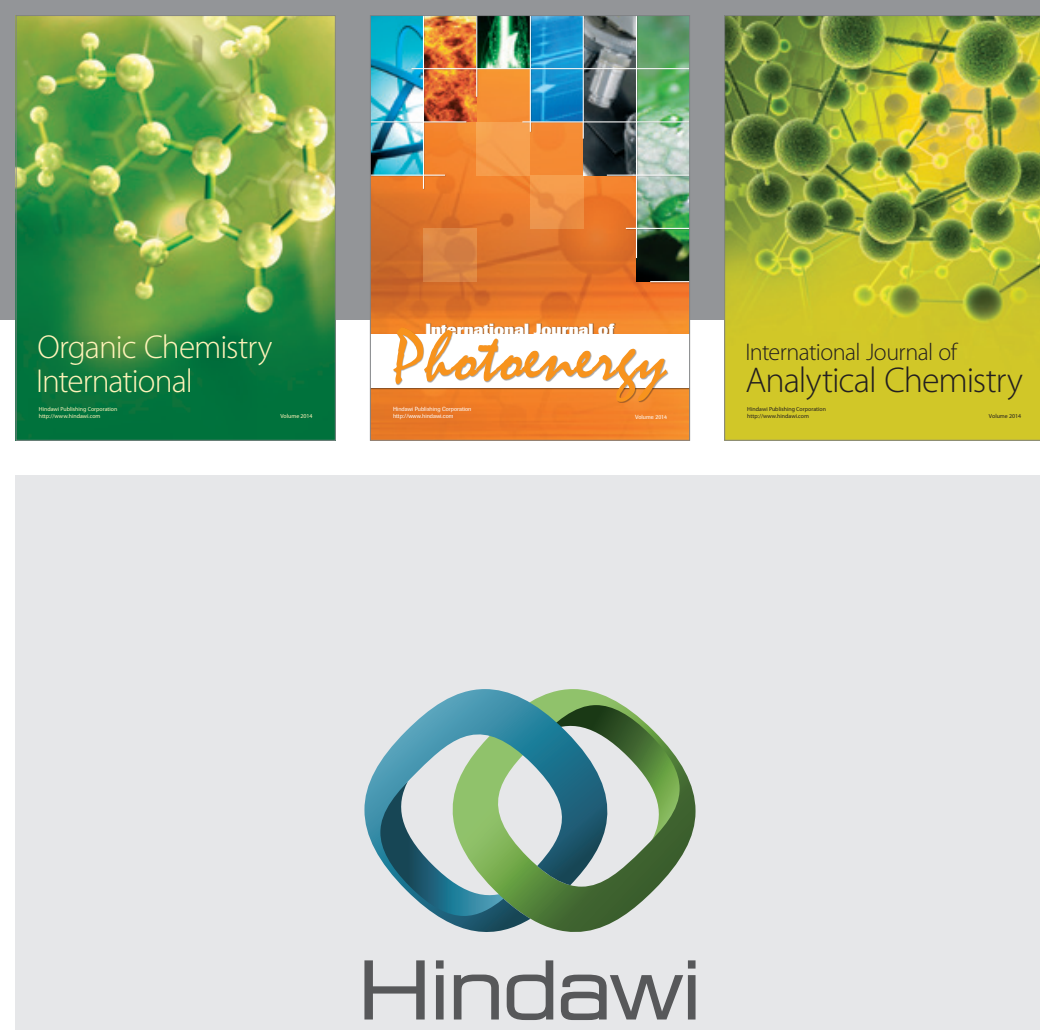

Submit your manuscripts at

http://www.hindawi.com
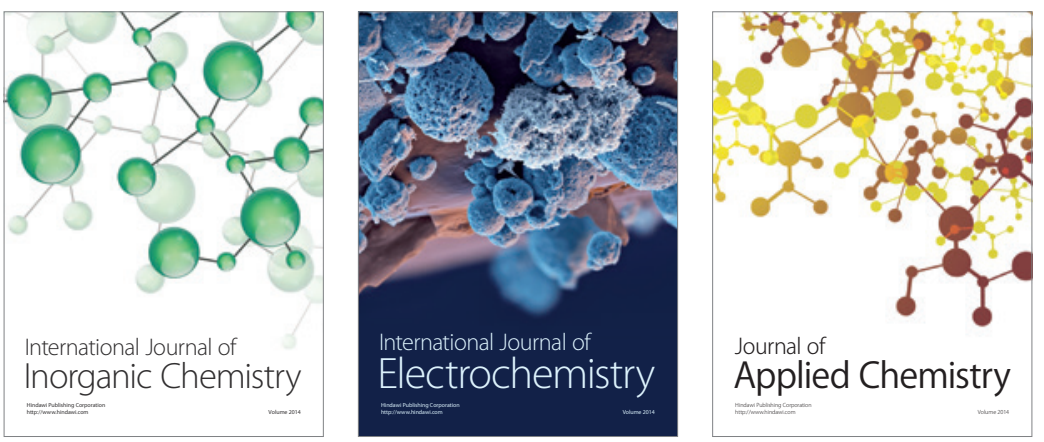

Journal of

Applied Chemistry
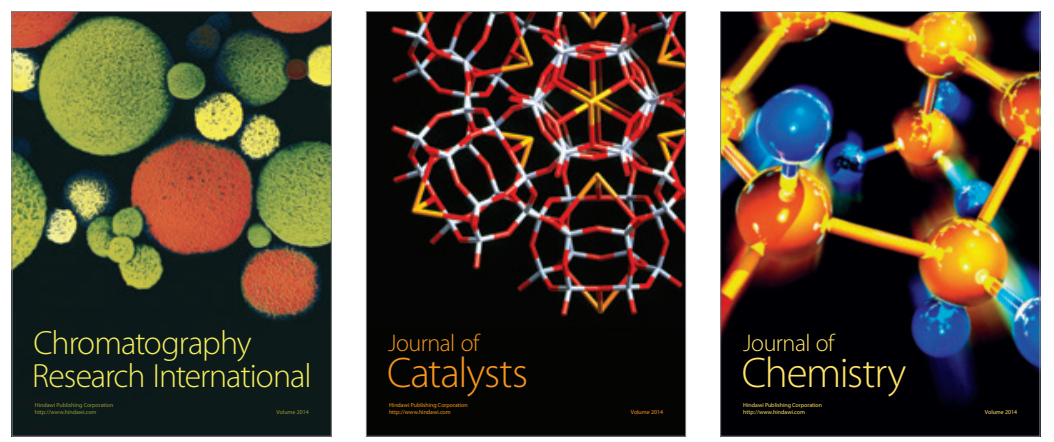
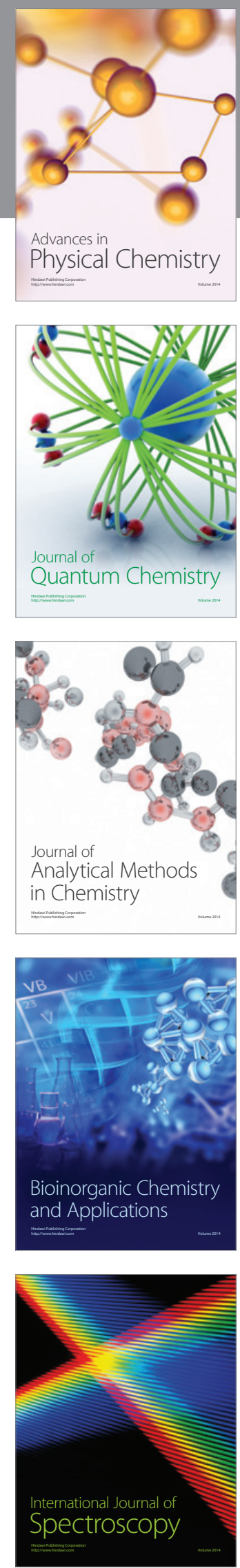